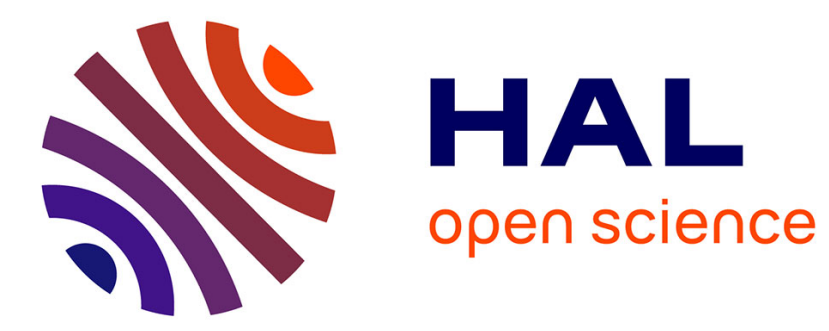

\title{
A new approach on the validation of the ESR fractional model
}

José Vanterler, Magun N., Edivilson Costa, L. Magna, E Capelas de Oliveira

\section{- To cite this version:}

José Vanterler, Magun N., Edivilson Costa, L. Magna, E Capelas de Oliveira. A new approach on the validation of the ESR fractional model. 2020. hal-02955495

\section{HAL Id: hal-02955495 \\ https://hal.science/hal-02955495}

Preprint submitted on 2 Oct 2020

HAL is a multi-disciplinary open access archive for the deposit and dissemination of scientific research documents, whether they are published or not. The documents may come from teaching and research institutions in France or abroad, or from public or private research centers.
L'archive ouverte pluridisciplinaire HAL, est destinée au dépôt et à la diffusion de documents scientifiques de niveau recherche, publiés ou non, émanant des établissements d'enseignement et de recherche français ou étrangers, des laboratoires publics ou privés. 


\title{
A new approach on the validation of the ESR fractional model
}

\author{
J. Vanterler da C. Sousa ${ }^{1, *}$, Magun N. N. dos Santos ${ }^{2}$, E. da $\operatorname{Costa}^{3}$, L. A. \\ Magna ${ }^{4}$ and E. Capelas de Oliveira ${ }^{5}$ \\ 1,5 Department of Applied Mathematics, Imecc-State University of Campinas, 13083-859, \\ Campinas, SP, Brazil \\ ${ }^{2,3}$ Department of Clinical Pathology, School of Medical Sciences, Unicamp, Campinas, SP \\ 13083-887, Brazil \\ ${ }^{4}$ Department of Medical Genetics, School of Medical Sciences, Unicamp, Campinas, SP \\ 13083-887, Brazil
}

\begin{abstract}
The main objective of this paper is to discuss a new approach for the validation of the fractional mathematical model that describes the erythrocyte sedimentation rate via a Caputo fractional diffusion equation. We discuss the data obtained in the laboratory and plot their respective graphs via the MATLAB 2010.a. Also, we performed an analysis of the graph plotted in two groups.

Keywords: Clinical laboratory tests, Erythrocyte sedimentation rate, Fractional calculus, Time-fractional diffusion equation.
\end{abstract}

2010 MSC: 26A06, 26A33, 33RXX, 34A30, 35KXX, 92BXX, 92DX.

\section{Introduction}

Sometime ago a mathematical model [1, integer model, to describes the concentration of nutrients in blood, a factor which influences erythrocyte sedimentation rate (ESR) was proposed. Recently, introducing in it a fractional

\footnotetext{
*Fully documented templates are available in the elsarticle package on CTAN

* Corresponding author

Email address: vanterlermatematico@hotmail.com, magnun@f cm.unicamp.br, edivilson@hc.unicamp.br, lamagna@uol.com.br, capelas@unicamp.br. (J. Vanterler da C. Sousa ${ }^{1, *}$, Magun N. N. dos Santos ${ }^{2}$, E. da $\operatorname{Costa}^{3}$, L. A. Magna ${ }^{4}$ and E. Capelas de Oliveira ${ }^{5}$ )
} 
derivative, was proposed a new 2], time-fractional mathematical model which contains, as a particular case, the integer model. This new model uses a Caputo fractional derivative to build a time-fractional diffusion equation suitable to predict blood sedimentation rates. An analytic solution of this time-fractional partial differential equation in terms of Mittag-Leffler and Wright functions was obtained, and the conclusion was that our model is more realistic than the integer one. More recently, the validation of our fractional mathematical model for ESR was presented and discussed [3].

This validation was carried out by means of erythrocyte sedimentation tests in laboratory. Data on sedimentation rates (percentages) were analyzed and compared with the analytical solution of the time-fractional diffusion equation. The behavior of the analytical solution related to each blood sample sedimentation data was described.

In 2018, Sousa et al. 3], presented a validation for the fractional mathematical model that describes the rate of sedimentation of erythrocytes with time evolution involving the Caputo fractional derivative. At that time, the authors were not concerned with the various types of pathologies that individuals ( 8 in total) had. As we know, not only various types of pathology that influence erythrocyte sedimentation, but also physical factors. Some results obtained in the analysis of the graphs generated from MATLAB 6.10, were good, others showed only a behavior similar to analytical solution of the fractional mathematical model. But in general, some of the graph curves, showed a behavior similar to the behavior of the analytical solution of the fractional model.

However, some questions from the previous article [3, had not yet been answered. A relevant and interesting question is: What would be the erythrocyte sedimentation rate of healthy individuals? This sedimentation rate, what behavior of the curves in the graphs? Would individuals behave similarly to the cases studied with individuals with pathologies? In this sense, motivated by these questions, we take a new approach in the validation of the fractional mathematical model [2] and discuss what are the consequences obtained when taking healthy individuals. 
Here we will highlight what are main contributions of this article, namely:

1. We obtained new tests in the laboratory and normalized the erythrocyte sedimentation data;

2. We present in detail the tables with the rates of the respective individuals;

3. We perform a rigorous analysis of the graphs generated from the data obtained in the laboratory and present in the tables.

Here, we compare the data considering only healthy individuals. The paper is organized as follows: in second section we recover our time-fractional mathematical model, described with a Caputo fractional derivative, that generalizes the mathematical model described with an integer derivative. In third section, our main result, we discuss the analytical solution considering only healthy individuals. Some graphics are presented and discussed and methods are also discussed. Concluding remarks close the paper.

\section{ESR fractional model}

In this section, we will briefly summarize the time-fractional mathematical model associated with erythrocyte sedimentation, as well as the methodology used in order to solve the partial differential equation that describes the model. To this end, we introduce the fractional derivative in the Caputo's sense in the time variable in order to write the fractional partial differential equation which is a generalization of the model involving the integer order derivative. From the methodology of the Laplace transform, in the time variable, we obtain an ordinary differential equation. We solve this differential equation and, from the respective inverse Laplace transform, we obtain the solution of the starting problem, expressed in terms of the Mittag-Leffler and Wright functions.

So, we started with the idea of $\psi$-Riemann-Liouville fractional integral with respect to another function. 
Definition 2.1. Let $\mu \in(0,1)$ and $\xi \in L^{1}[a, b],[a, b]$ be a finite or infinite interval of the real line $\mathbb{R}(-\infty \leq a<b \leq \infty)$. Also let $\psi(\cdot)$ be an increasing and positive continuous function on $[a, b]$, having a continuous derivatives $\psi^{\prime}(x) \neq 0$ on $(a, b)$. The left and right-sided fractional integrals of a function $f$ with respect to another function $\psi$ on $[a, b]$, is defined [4, 5]

$$
\mathbf{I}_{a+, x}^{\mu ; \psi} f(x)=\frac{1}{\Gamma(\mu)} \int_{a}^{x} \psi^{\prime}(t)(\psi(x)-\psi(t))^{\mu-1} f(t) d t .
$$

Choosing $\psi(x)=x$ in Eq. (1), we have the Riemann-Liouville fractional integral given by

$$
\mathbf{I}_{a+, x}^{\mu} f(x)=\frac{1}{\Gamma(\mu)} \int_{a}^{x}(x-t)^{\mu-1} f(t) d t .
$$

Also, we introduce the $\psi$-Hilfer fractional derivative.

Definition 2.2. Let $n-1<\mu<n$, with $n \in \mathbb{N}, I=[a, b]$, is the interval such that $-\infty \leq a<b \leq \infty$ and there exist two function $f, \psi \in C^{n}([a, b], \mathbb{R})$ such that $\psi$ is increasing and $\psi^{\prime}(x) \neq 0$, for all $x \in I$. The $\psi$-Hilfer fractional derivatives left-sided and right-sided ${ }^{H} \mathbb{D}_{a+, x}^{\mu, \beta ;}(\cdot)$ function of order $\mu$ and type $0 \leq \beta \leq 1$ is defined by [4, [5]

$$
{ }^{H} \mathbb{D}_{a+, x}^{\mu, \beta ; \psi} \xi(x)=\mathbf{I}_{a+, x}^{\beta(n-\mu) ; \psi}\left(\frac{1}{\psi^{\prime}(x)} \frac{d}{d x}\right)^{n} \mathbf{I}_{a+, x}^{(1-\beta)(n-\mu) ; \psi} \xi(x) .
$$

Also here, choosing $\psi(x)=x$ and taking the limit $\beta \rightarrow 1$ in Eq. (3), we have the Caputo fractional derivative, given by [4, 5]

$$
\mathcal{D}_{a+, x}^{\mu} f(x)=\mathbf{I}_{a+, x}^{\beta(n-\mu)}\left(\frac{d}{d x}\right) f(x) .
$$

The Caputo fractional derivative Eq. (4), will be used for the formulation of the fractional mathematical model, as we will see below.

In this model, the concentration of nutrients in blood is a function $C(x, t)$ twice continuously differentiable that satisfies the following non-homogeneous time-fractional partial differential equation,

$$
D_{L} \mathcal{D}_{x}^{2} C(x, t)-\mathcal{D}_{t}^{\mu} C(x, t)=\phi(x, t)
$$


with $0<\mu \leq 1$, where $\mathcal{D}_{t}^{\mu} \equiv \frac{\partial^{\mu}}{\partial t^{\mu}}$, and $D_{L}$ is a positive constant and $\phi(x, t)$ is a twice continuously differentiable function describing the nutrient rate and which satisfies the following partial differential equation

$$
D \mathcal{D}_{x}^{2} \phi(x, t)-k \phi(x, t)-\mathcal{D}_{t} \phi(x, t)=0
$$

with both $D$ and $k$ positive constants.

The initial and boundary conditions imposed on $\phi(x, t)$ are given by

$$
\left\{\begin{aligned}
\phi(x, 0) & =\exp \left(-\sqrt{\frac{k-a}{D} x}\right), k \geq a, D>0 \\
\phi(0, t) & =\exp (-a t), t>0 \\
\phi(\infty, t) & =0, t>0
\end{aligned}\right.
$$

On the other hand, we assume that the fractional derivative of order $0<\mu \leq 1$ is considered in the Caputo sense, defined as follow

$$
\mathcal{D}_{t}^{\mu} C(x, t):= \begin{cases}\frac{1}{\Gamma(1-\mu)} \int_{0}^{t} \frac{\mathrm{d}}{\mathrm{d} \tau} C(x, \tau)(t-\tau)^{-\mu} \mathrm{d} \tau & 0<\mu<1 \\ \frac{\mathrm{d}}{\mathrm{d} t} C(x, t) & \mu=1\end{cases}
$$

Furthermore, we must impose the initial and boundary conditions for Eq. (5)

$$
\left\{\begin{aligned}
C(x, 0) & =0, x \geq 0 \\
C(0, t) & =1, t>0 \\
C(\infty, t) & =0, t>0 .
\end{aligned}\right.
$$

As we have already said, we use the methology of the Laplace transform to obtain the analytic solution of starting problem, then we get

$$
\begin{aligned}
C(x, t)= & t^{\mu} \sum_{m=0}^{\infty} \frac{\left(-\alpha x t^{-\mu / 2}\right)^{m}}{m !} \sum_{k=0}^{\infty}(-a t)^{k} \mathbb{E}_{\mu, \mu+k+1-\mu m / 2}\left(\beta^{2} t^{\mu}\right)+ \\
& +\mathbb{W}\left(-\mu / 2,1 ;-\frac{\alpha x}{t^{\mu / 2}}\right)-\exp (-b x) t^{\mu} \sum_{k=0}^{\infty}(-a t)^{k} \mathbb{E}_{\mu, \mu+k+1}\left(\beta^{2} t^{\mu}\right)
\end{aligned}
$$

where we have introduced the parameters $\alpha^{2}=1 / D_{L}, \beta^{2}=b^{2} D_{L}$, being $b^{2}=$ $(k-a) / D>0$ and $a$ a constant to be adequately chosen from a know value 
of $\phi(x, t)$. Also, $\mathbb{E}_{\xi, \eta}(\cdot)$ and $\mathbb{W}(\gamma, \delta ; \cdot)$ are the Mittag-Leffler function with two parameters and the Wright function, respectively. For a more detailed reading of the model and the analytical solution, we suggest $[3$.

The solution given by Eq.(6), valid for $t>0$, is absolutely continuous; then, substituting it into Eq. (5) we can easily verify that it satisfies the initial value problem and boundary value problem [6]. Also, in reference [2] one can see a graphical analysis and the solution of the integer case, recovered as the limit $\mu \rightarrow 1$, as a particular case of Eq. (6).

In another recent paper [3] after a brief introduction to a fractional mathematical model used to describe the blood concentration of nutrients that influence the sedimentation rate of blood cells, we have presented the results of laboratory ESR tests with eight samples, four males and four females, used to validate that mathematical model.

For this sake, the results of sedimentation tests were compared, through graphical analysis, with the analytical solution of the mathematical model. Only eight samples were enough to carry out this comparison and discuss the model. However, more tests, providing new data, would surely allow a better comprehension of the fractional mathematical model, making it more appropriate to describe reality.

We note that, a remarkable advantage of the fractional mathematical model is the freedom to choose the order of the derivative in it and, consequently, the analytical solution of the problem. With the freedom given to the parameter $0<\mu \leq 1$, we were able to analyze the concentration of nutrients on certain intervals and regions in which the integer mathematical model cannot be used. Our model can thus provide information on the blood concentration of nutrients closer to reality. As we also mentioned [3] another possibility was proposed during the experiments, i.e., to perform the tests with healthy individuals only, as we will see in the next section, and apply to them the same procedure used here.

In the next section, we will take a new approach regarding the validation of the fractional mathematical model Eq. (5). 


\section{A new approach on the validation of the fractional model}

In this section we discuss a new approach in the validation of the mathematical fractional model which was investigated in 2017 by Sousa et al. 2]. In order to discuss in more detail the fractional mathematical model validation we carry out laboratory tests in samples from 28 healthy subjects (14 females and 14 males). Data tables and graphs thus obtained are shown in descriptive result analysis.

A short review is necessary. The erythrocyte sedimentation rate is a blood test that assists in the diagnosis of the acute phase of inflammatory diseases and also enables the monitoring of inflammation. The test is not very reliable, so further testing is necessary to confirm the accuracy of the results. The need for further testing is due to the fact that analytical factors influence the results, leading to false negative and false positive results. Today, since we have more modern and more accurate devices, ESR (VHS hemosedimentation rate) testing is restricted to a few cases.

\subsection{Materials and Methods}

The ESR tests were conducted at the Hematology Laboratory of the Clinical Hospital, State University of Campinas, state of São Paulo, southeast Brazil. It was obtained a random sample of 28 healthy subjects (14 females and 14 males) from whom a blood sample was picked up and placed in sedimentation tubes, the erythrocyte sedimentation rate (ESR) in millimeters being record at 5 -minutes interval from 5 up to 70 minutes.

In 2018 Sousa et al. [3] carried out laboratory tests in order to validate the fractional mathematical model Eq. (5) which was introduced in 2017 by Sousa et al. 2].

At that time, the authors performed a test with individuals of both sex male and female, however they were not concerned with the various types of pathologies that influence the ESR test. Factors such as table tilt and room temperature are considered independent pathological factors. Although we know that these 
physical factors also change the ESR. However, in order to avoid these possible changes were considered a temperature of $22^{\circ} \mathrm{C}$ and the platform on which the tests were carried out, with the support that contained the pipettes, had an angle of $90^{\circ}$. In this sense, the tests performed for the discussion and data analysis, were also considered in this context, that is, a temperature of $22^{\circ} \mathrm{C}$ and an angle of $90^{\circ}$ between the table and the pipette holder.

The first step in carrying out the tests was to choose individuals (female and male) without any type of pathology, since one of the main objectives is to know how the erythrocyte sedimentation rate behaves in this group of people. After, we separated into two groups, each containing 14 people with their respective tubes containing the blood which we would carry out the tests. In this sense, we started the tests in two stages. In the first step, we analyzed the erythrocyte sedimentation rate of 14 individuals, with a time interval of 5 minutes. Then we converted the height for the sedimentation rate to percentages. The choice of 5 minutes, comes from the fact that in shorter times, sedimentation was very little and was often not noticeable in the test tube (the scale of the test tube is in $\mathrm{mm}$ ). From the notes made every 5 minutes of the 28 individuals, we separated the sedimentation rates into two tables, explaining the following points: sex (we denote by $\mathrm{M}=$ Male and $\mathrm{F}=$ Female), age, time and sedimentation rate. So, we have the following two tables.

Some points that we can highlight from both tables. First, the maximum and minimum age for men in the tests performed are $I d_{\max }=67$ years and $I d_{\text {min }}=27$, respectively, with an average age $I d_{\text {med }}=41,64$ years. On the other hand, the maximum and minimum age for women in the tests performed are $I d_{\max }=34$ years and $I d_{\min }=20$, respectively, with an average age of $I d_{m e d}=27,92$ years. We can also highlight the average age in general without considering the type of gender (male and female), which is given by $I d_{m e d}=$ 34,78 .

To sketch the graphs using the MATLAB R2010a software, we first normalized the data obtained in the laboratory tests. Further, we normalized the unit to the value of the sedimentation rate obtained, dividing by its highest sedimen- 
Table 1: Erythrocyte Sedimentation Rate - Male

\begin{tabular}{|c|c|c|c|c|c|c|c|c|c|c|c|c|c|c|c|c|c|}
$\mathrm{ID}$ & $\mathrm{Sex}$ & Time/Age & 05 & 10 & 15 & 20 & 25 & 30 & 35 & 40 & 45 & 50 & 55 & 60 & 65 & 70 & \\
\hline 01 & $\mathrm{M}$ & 35 & 0 & 1 & 1 & 1 & 1 & 1 & 2 & 2 & 3 & 3 & 4 & 5 & 6 & 6 & \\
02 & $\mathrm{M}$ & 41 & 1 & 2 & 2 & 2 & 2 & 3 & 3 & 3 & 4 & 5 & 5 & 6 & 8 & 10 & \\
03 & $\mathrm{M}$ & 51 & 0 & 1 & 1 & 2 & 2 & 3 & 4 & 4 & 5 & 5 & 7 & 8 & 10 & 12 & \\
04 & $\mathrm{M}$ & 27 & 0 & 1 & 1 & 1 & 2 & 3 & 3 & 4 & 5 & 6 & 7 & 8 & 11 & 12 & \\
05 & $\mathrm{M}$ & 40 & 0 & 1 & 2 & 2 & 3 & 4 & 5 & 6 & 8 & 11 & 13 & 17 & 20 & 23 & \\
06 & $\mathrm{M}$ & 67 & 0 & 1 & 2 & 2 & 4 & 6 & 9 & 13 & 17 & 20 & 24 & 28 & 31 & 34 & $\mathrm{E}$ \\
07 & $\mathrm{M}$ & 35 & 1 & 1 & 1 & 2 & 2 & 3 & 4 & 5 & 8 & 10 & 13 & 17 & 21 & 23 & $\mathrm{~S}$ \\
08 & $\mathrm{M}$ & 51 & 0 & 1 & 1 & 1 & 1 & 2 & 2 & 2 & 3 & 3 & 3 & 3 & 3 & 4 & $\mathrm{R}$ \\
09 & $\mathrm{M}$ & 50 & 0 & 0 & 1 & 1 & 1 & 2 & 3 & 3 & 3 & 3 & 4 & 4 & 4 & 4 & \\
10 & $\mathrm{M}$ & 41 & 1 & 1 & 1 & 2 & 3 & 3 & 4 & 6 & 8 & 10 & 12 & 14 & 17 & 18 & \\
11 & $\mathrm{M}$ & 47 & 1 & 1 & 1 & 2 & 3 & 3 & 5 & 8 & 10 & 13 & 17 & 20 & 23 & 26 & \\
12 & $\mathrm{M}$ & 20 & 0 & 0 & 1 & 1 & 1 & 2 & 3 & 4 & 4 & 4 & 5 & 5 & 6 & 7 & \\
13 & $\mathrm{M}$ & 43 & 1 & 2 & 2 & 2 & 3 & 3 & 4 & 5 & 6 & 8 & 12 & 16 & 18 & 22 & \\
14 & $\mathrm{M}$ & 35 & 1 & 2 & 2 & 3 & 3 & 4 & 5 & 7 & 10 & 13 & 16 & 18 & 21 & 24 &
\end{tabular}

tation value obtained in the tests in order to compare with the graph obtained from the analytical solution of the fractional partial differential equation. In the three graphs, the horizontal axis, $x$, in centimeters, represents the normalized distance in the pipette while on the vertical axis, $y$, the sedimented amount normalized to the unit.

\subsection{Discussions and results}

In this section, we will perform an analysis of the plotted graphs using the MATLAB 2010a tool, obtained through laboratory data. Let's separate the analyzes into two groups: Group 1, are the individuals whose sedimentation rate had an interesting and important behavior in comparison with the fractional mathematical model. Group 2, are the individuals that their sedimentation rates, had sudden oscillations and thus, their data are not considered good for 
Table 2: Erythrocyte Sedimentation Rate - Female

\begin{tabular}{|c|c|c|c|c|c|c|c|c|c|c|c|c|c|c|c|c|c|} 
ID & Sex & Time/Age & 05 & 10 & 15 & 20 & 25 & 30 & 35 & 40 & 45 & 50 & 55 & 60 & 65 & 70 & \\
\hline 01 & $\mathrm{~F}$ & 31 & 1 & 2 & 3 & 4 & 4 & 5 & 6 & 8 & 11 & 13 & 15 & 17 & 21 & 22 & \\
02 & $\mathrm{~F}$ & 28 & 0 & 0 & 1 & 1 & 2 & 2 & 3 & 3 & 4 & 5 & 7 & 8 & 10 & 11 & \\
03 & $\mathrm{~F}$ & 28 & 2 & 3 & 3 & 3 & 4 & 4 & 4 & 6 & 7 & 9 & 12 & 17 & 19 & 21 & \\
04 & $\mathrm{~F}$ & 20 & 1 & 1 & 2 & 2 & 4 & 8 & 12 & 17 & 23 & 27 & 33 & 42 & 42 & 46 & \\
05 & $\mathrm{~F}$ & 32 & 0 & 1 & 1 & 2 & 2 & 3 & 4 & 4 & 5 & 7 & 8 & 9 & 10 & 12 & \\
06 & $\mathrm{~F}$ & 25 & 1 & 1 & 1 & 2 & 2 & 4 & 5 & 6 & 8 & 10 & 12 & 16 & 18 & 19 & $\mathrm{E}$ \\
07 & $\mathrm{~F}$ & 27 & 1 & 1 & 1 & 1 & 2 & 3 & 3 & 4 & 5 & 6 & 6 & 8 & 9 & 10 & $\mathrm{~S}$ \\
08 & $\mathrm{~F}$ & 26 & 0 & 1 & 2 & 2 & 4 & 4 & 7 & 9 & 11 & 14 & 17 & 21 & 23 & 26 & $\mathrm{R}$ \\
09 & $\mathrm{~F}$ & 23 & 0 & 0 & 0 & 1 & 2 & 3 & 4 & 5 & 7 & 9 & 12 & 15 & 17 & 20 & \\
10 & $\mathrm{~F}$ & 30 & 1 & 1 & 2 & 3 & 4 & 8 & 8 & 16 & 19 & 24 & 27 & 33 & 36 & 41 & \\
11 & $\mathrm{~F}$ & 32 & 1 & 1 & 2 & 2 & 3 & 3 & 4 & 5 & 7 & 8 & 10 & 12 & 14 & 17 & \\
12 & $\mathrm{~F}$ & 28 & 0 & 0 & 1 & 1 & 3 & 3 & 6 & 10 & 14 & 18 & 22 & 26 & 31 & 35 & \\
13 & $\mathrm{~F}$ & 34 & 1 & 1 & 1 & 2 & 2 & 3 & 3 & 5 & 7 & 10 & 13 & 15 & 18 & 21 & \\
14 & $\mathrm{~F}$ & 27 & 1 & 2 & 2 & 2 & 3 & 4 & 4 & 4 & 5 & 5 & 7 & 8 & 8 & 10 &
\end{tabular}

model validation.

At first we can highlight in general that the graphics of this Group 1, its curves have a behavior similar to family of solutions of the fractional mathematical model. An important characteristic is that in this new experiment, the data obtained for male individuals, had a better performance compared to female individuals. Although age influences the erythrocyte sedimentation rate, here are good results for the data collected.

Some graphs deserve special mention, and we will analyze the following graphs $H 2, H 3, H 5, H 8, M 4$ and $M 12$.

The first two graphs are for male individuals and they show better behavior when compared to the curves of the fractional model. Both individuals are over 40 years old, this factor may have influenced the sedimentation rate. On the other hand, the two female individuals in which the behavior of the sedimenta- 
tion rate curve that best accompanied the analytical solution of the fractional model, were $M 4$ and $M 12$, which in turn, unlike the male case, both are under 30 years old. In general, the chart that had the most relevant behavior was the M4 chart. Another important fact worth mentioning, follows from the article [3] and the graphs discussed in this article, in both works, the female sedimentation rate, had better results, when compared with the male.

On the other hand, Group 2, the data obtained in the laboratory and consequently plotted, did not obtain good results in the sense that the graph curves behave similarly, the solution curves of the fractional mathematical model. Note that all curves in this second group have a sharp drop. This fact is due to the sedimentation rate it was parked for several minutes without adding, or when it is added, it is small and it took a while for this to happen. In particular, a similar characteristic of this type of graph, is the permanence in the first 20 minutes, with its sedimentation rate stationary at 1 . So, having this type of characteristic, we can already conclude that the graph generated by the sedimentation rate, will not provide a considerable analysis for the validation of the fractional model. It should be noted that individuals are healthy and that age is a factor that can also influence sedimentation.

\subsection{Casuistic}

It was obtained a random sample of 28 healthy subjects ( 14 females and 14 males) from whom a blood sample was picked up and placed in sedimentation tubes, the ESR in millimeters being recorded at 5-minutes interval from 5 up to 70 minutes. The variables age and ESR recorded as stated were tested for normality according to Kolmogorov-Smirnov test, and with exception to ESR at times 5, 10, 15, 20 and 30, all others did fit to a normal distribution with $p$-value greater than the significant value adopted $(p>0,05)$. The mean data according to gender were compared by either Student's t test (after Levene's test for variance equality) whenever normally distributed, or by Mann-Whitney test whenever not, as is shown in Table 1. Since female and male samples significantly differed with respect to age, the influence of the latter on ESR at 
each point recorded was evaluated by Pearson's correlation method and there was no significant correlation to age $(p>0,05)$ in all cases.

Thus the sample at each measured point recorded can be suitable represented by its average value, and also joined together to an overall average value regardless of gender and age.

Table 3: Average values and comparison according to age.

\begin{tabular}{|c|c|c|c|c|c|} 
Gender & Female & Male & Overall & $\mathrm{p}$ value & Statistical test \\
\hline Age & 27,9286 & 41,6429 & 34,7857 & 0,001 & Student's t \\
t5 & 0,7143 & 0,4286 & 0,5714 & 0,285 & Mann-Whitney \\
t10 & 1,0714 & 1,0714 & 1,0714 & 0,874 & Mann-Whitney \\
t15 & 1,5714 & 1,3571 & 1,4643 & 0,511 & Mann-Whitney \\
t20 & 2,0000 & 1,7143 & 1,8571 & 0,482 & Mann-Whitney \\
t25 & 2,9286 & 2,2143 & 2,5714 & 0,056 & Student's t \\
t30 & 4,0714 & 3,0000 & 3,5357 & 0,077 & Mann-Whitney \\
t35 & 5,2143 & 4,0000 & 4,6071 & 0,147 & Student's t \\
t40 & 7,2857 & 5,1429 & 6,2143 & 0,139 & Student's t \\
t45 & 9,5000 & 6,7143 & 8,1071 & 0,140 & Student's t \\
t50 & 11,7857 & 8,1429 & 9,9643 & 0,120 & Student's t \\
t55 & 14,3571 & 10,1429 & 12,2500 & 0,130 & Student's t \\
t60 & 17,6429 & 12,0714 & 14,8571 & 0,109 & Student's t \\
t65 & 19,7143 & 14,2143 & 16,9643 & 0,136 & Student's t \\
t70 & 22,2143 & 16,0714 & 19,1429 & 0,132 & Student's t
\end{tabular}


Figure 1: Graph of the average of the data of Men.

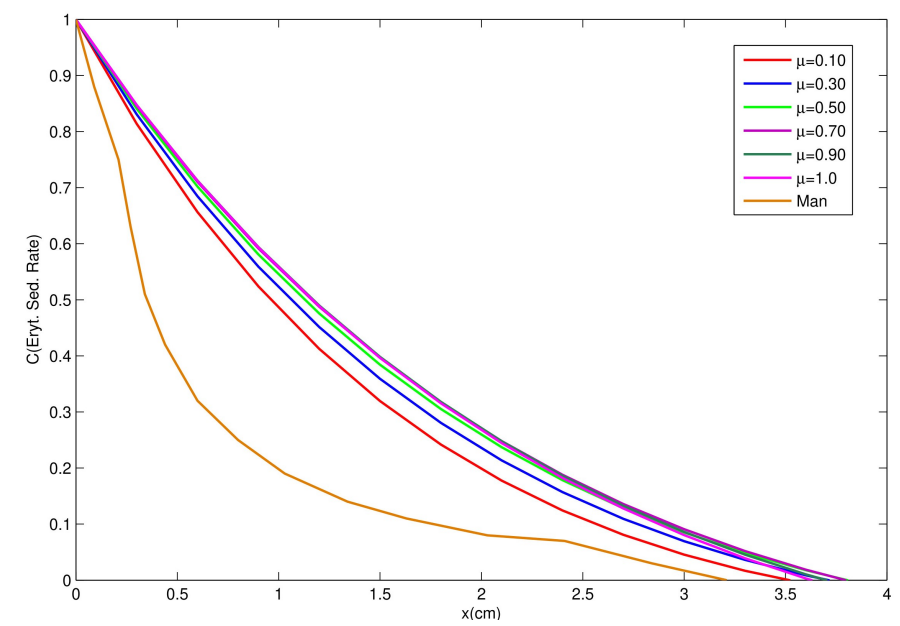

Figure 2: Graph of the average of the data of Woman.

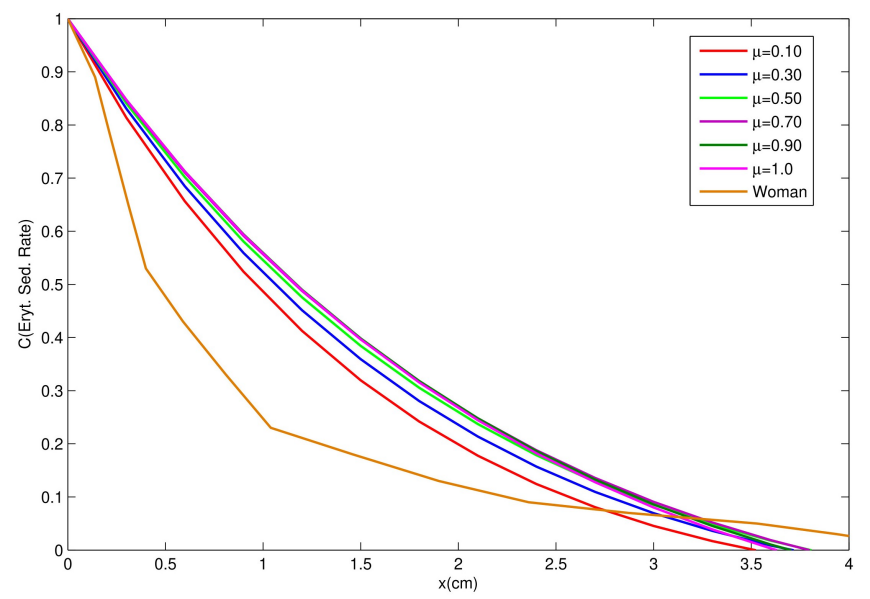

\section{Concluding remark and future work}

We conclude the paper, with the objectives obtained, that is, the results of the analysis of the graphs that refer to the erythrocyte sedimentation rate of male and female individuals, were satisfactory with the tools used here, namely: laboratory tests, tables, MATLAB 6.10 and graphs. However, as we know, it is not an easy and trivial task to model natural phenomena via differential, in 
Figure 3: Graph the average of the data of Overall

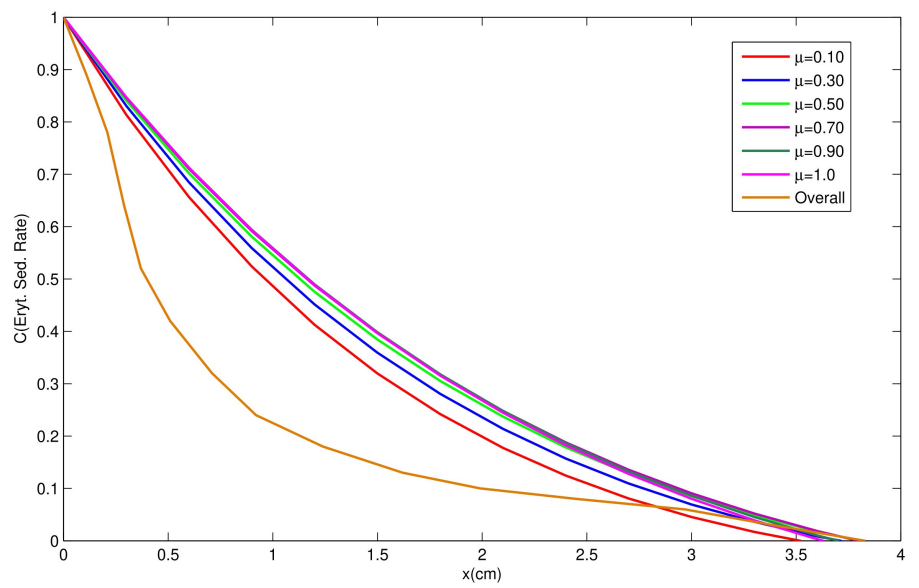

particular, fractional differential equations. Here we use the non-variable Caputo fractional derivative to model the erythrocyte sedimentation rate. But we can ask, if in fact Caputo fractional derivative is the best option. For example, instead of choosing the order of the derivative as a number, and start working with the order being functions. We could think of finding a function that best suits the objectives discussed here. Some recent studies have presented new fractional derivatives, for example, the $\psi$-Hilfer fractional derivative of nonvariable order and variable order. One way to overcome the above question is to use more general fractional operators, containing the usual cases as particular cases. Studies in this sense have been carried out via fractional derivatives (Sousa, Tenreiro and de Oliveira [7] and Sousa and de Oliveira [8, 4]), namely, a general problem of fractional space diffusion. After that, we shall carry out the same sedimentation tests and shall use their results to analyze the capabilities of that new model for describing real living systems.

\section{Acknowledgment}

J. Vanterler acknowledges the financial support of a PNPD-CAPES (number of process n $\left.{ }^{\circ} 88882.305834 / 2018-01\right)$ scholarship of the Postgraduate Program in 
Applied Mathematics of IMECC-Unicamp.

\section{References}

[1] G. C. Sharma, M. Jain, R. N. Saral, A mathematical model for concentration of blood affecting erythrocyte sedimentation, Comput. Biology Med. 26 (1) (1996) $1-7$.

[2] J. Vanterler da C. Sousa, E. Capelas de Oliveira, L. A. Magna, Fractional calculus and the esr test, AIMS Math. 2 (4) (2017) 292-705.

[3] J. Vanterler da C. Sousa, M. N. N. dos Santos, L. A. Magna, E. Capelas de Oliveira, Validation of a fractional model for erythrocyte sedimentation rate, Comput. Appl. Math. 37 (5) (2018) 6903-6919.

[4] J. Vanterler da C. Sousa, E. Capelas de Oliveira, On the $\psi$-Hilfer fractional derivative, Commun. Nonlinear Sci. Numer. Simul. 60 (2018) 72-91.

[5] J. Vanterler da C. Sousa, E. Capelas de Oliveira, Leibniz type rule: $\psi$-Hilfer fractional operator, Commun. Nonlinear Sci. Numer. Simul. 77 (2019) 305311.

[6] J. Vanterler da C. Sousa, Erythrocyte sedimentation: A fractional model, Phd Thesis, Imecc-Unicamp, Campinas (2017).

[7] J. Vanterler da C. Sousa, J. A. Tenreiro Machado, E. Capelas de Oliveira, The $\psi$-Hilfer fractional calculus of variable order and its applications, Comput. Appl. Math. (Accept) (2020).

[8] J. Vanterler da C. Sousa, E. Capelas de Oliveira, Two new fractional derivatives of variable order with non-singular kernel and fractional differential equation, Comput. Appl. Math. 37 (4) (2018) 5375-5394. 
Figure 4: Graph of the data Man 3.

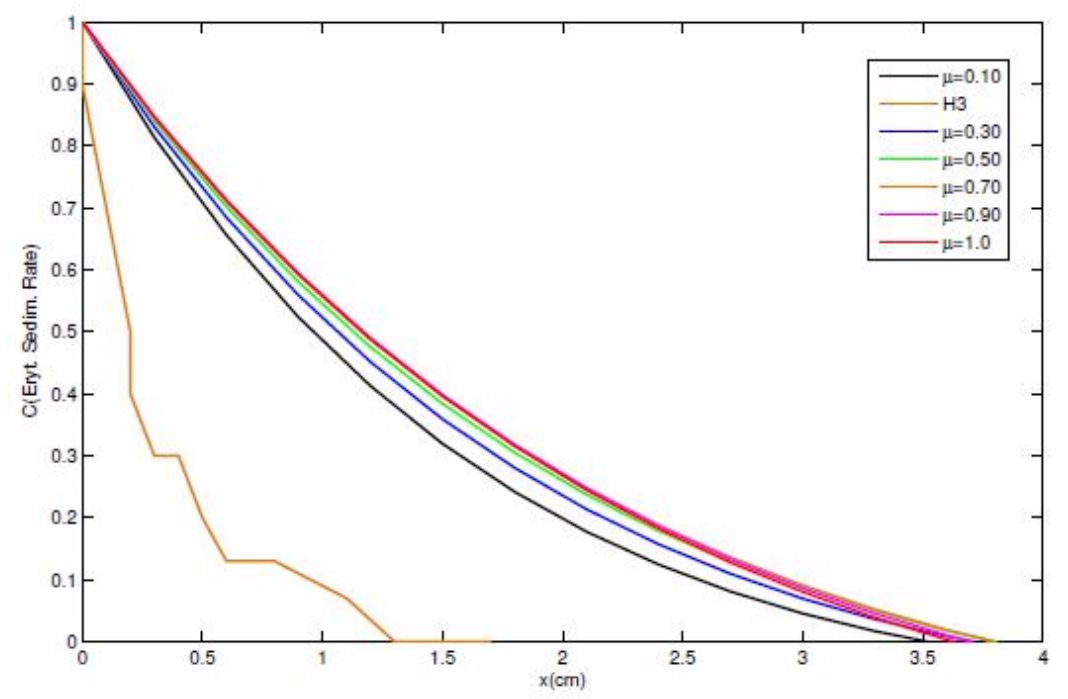

Figure 5: Graph of the data Man 5.

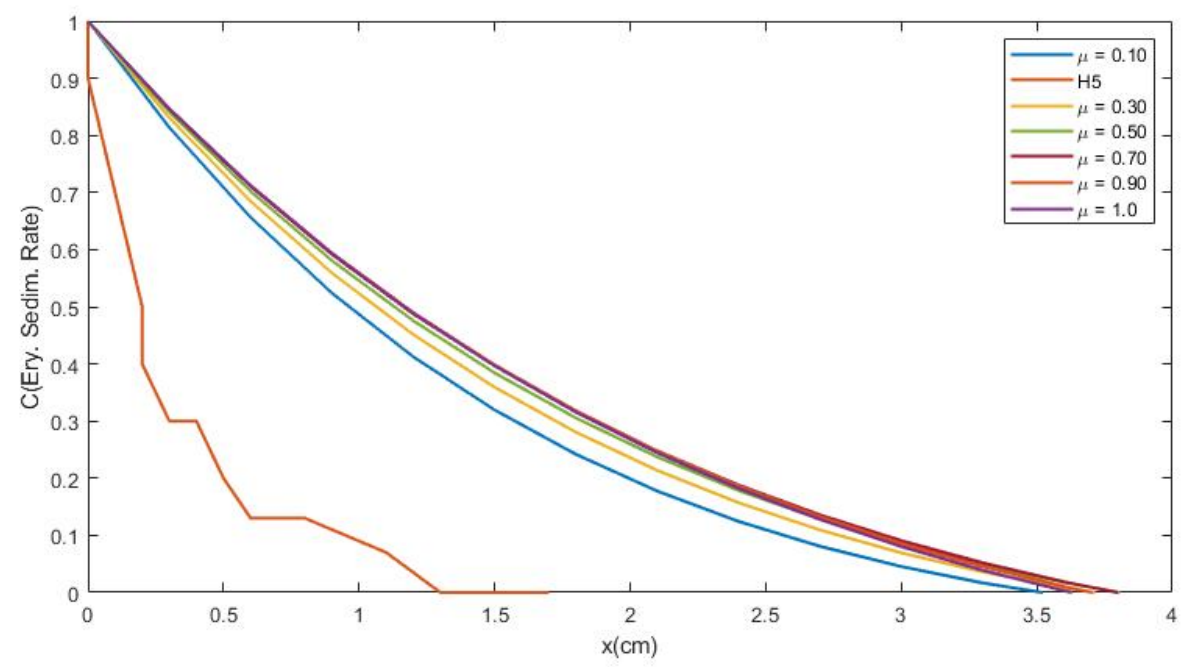


Figure 6: Graph of the data Man 1.

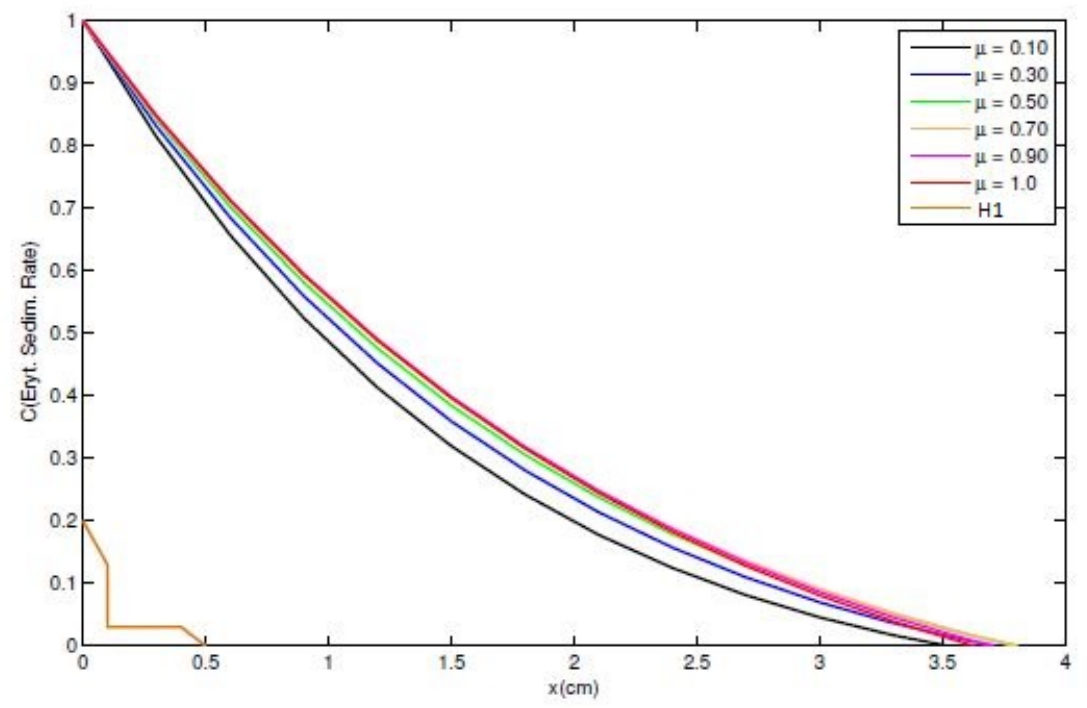

Figure 7: Graph of the data Man 2.

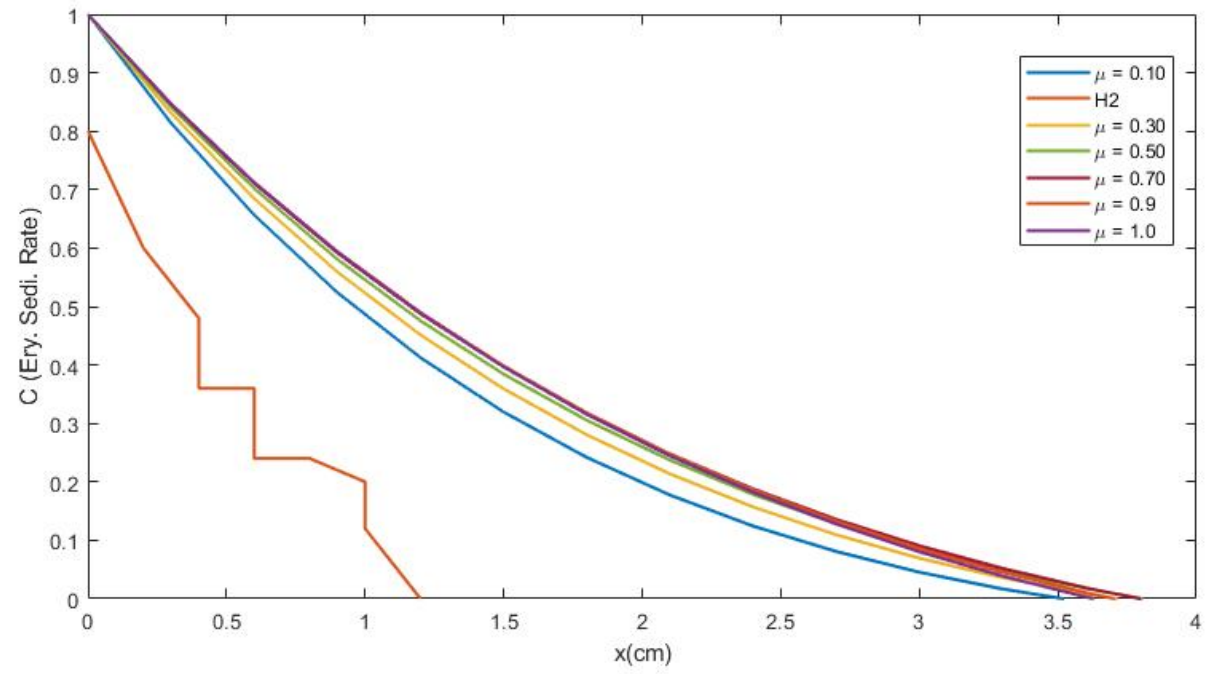


Figure 8: Graph of the data Man 4.

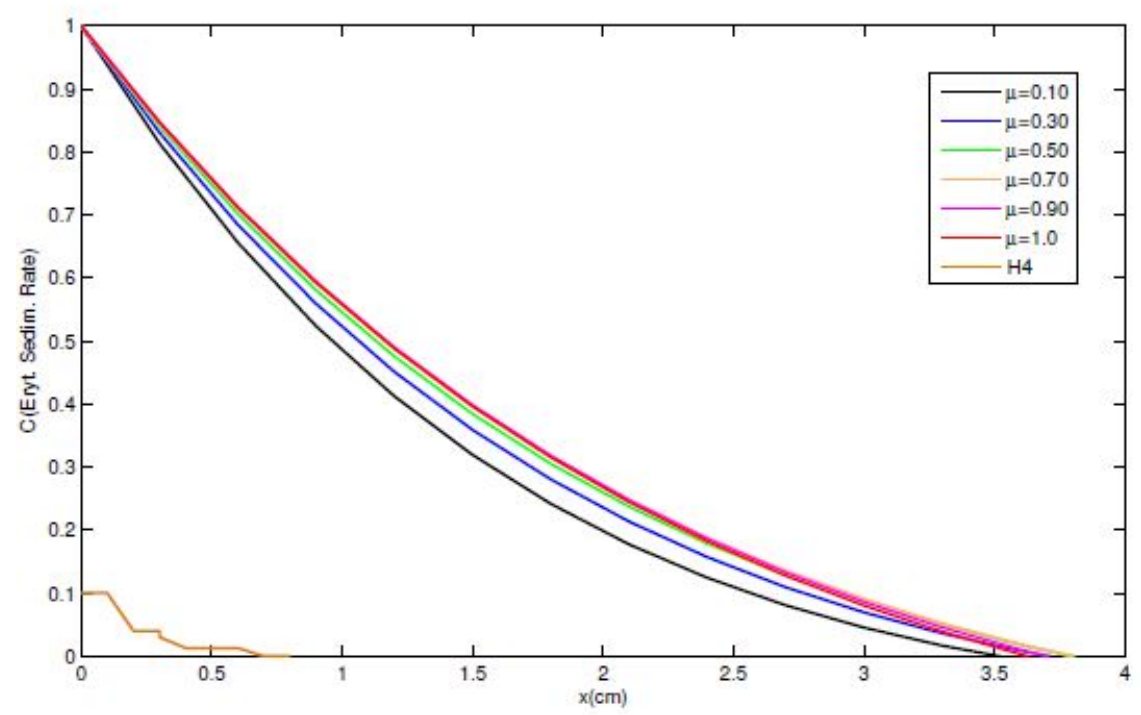

Figure 9: Graph of the data Man 6.

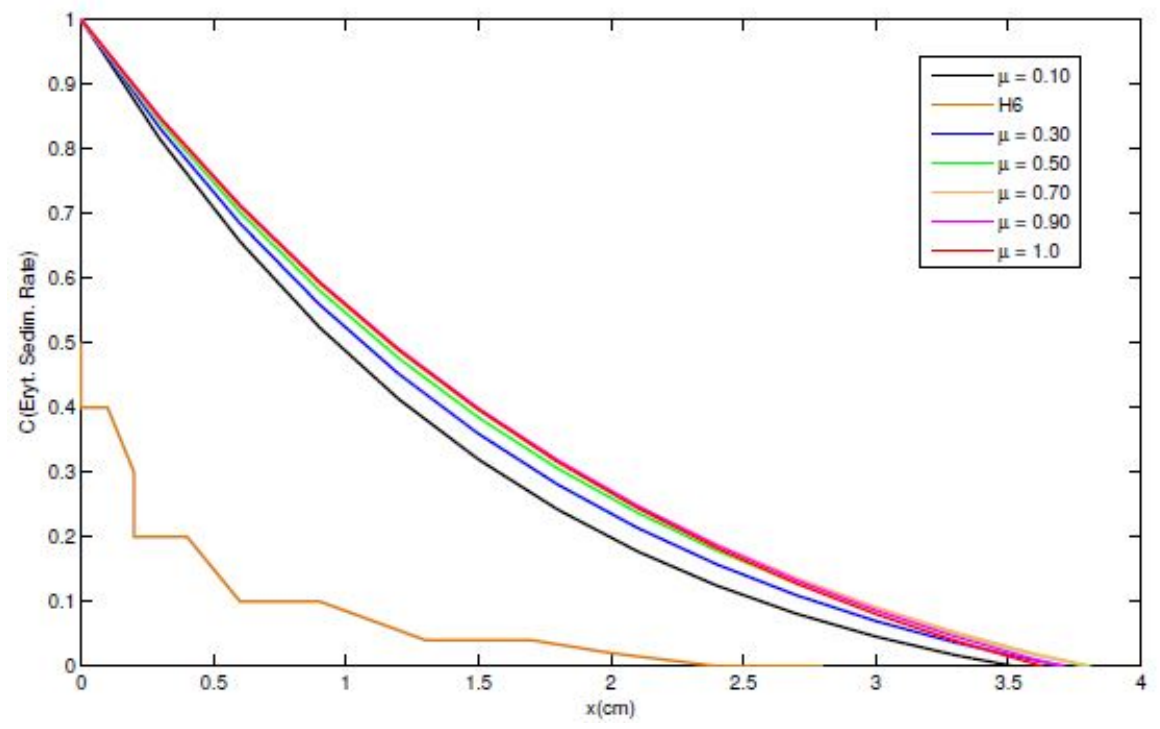


Figure 10: Graph of the data Man 8.

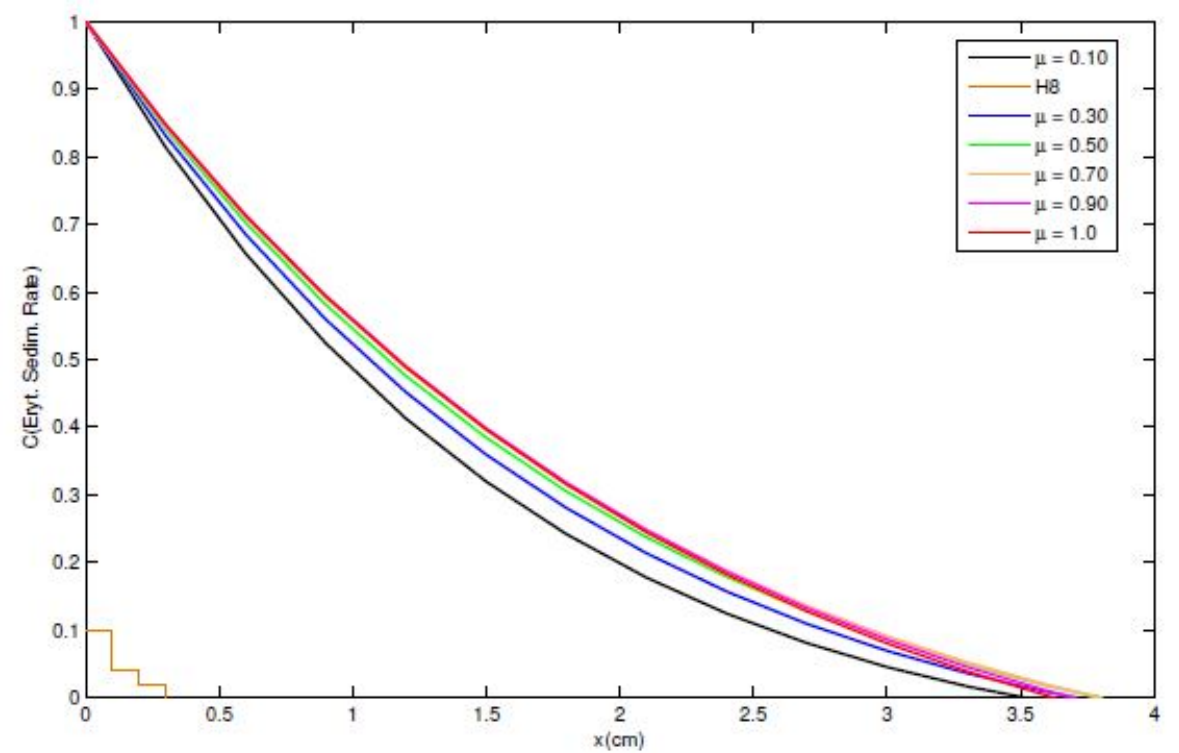

Figure 11: Graph of the data Man 10.

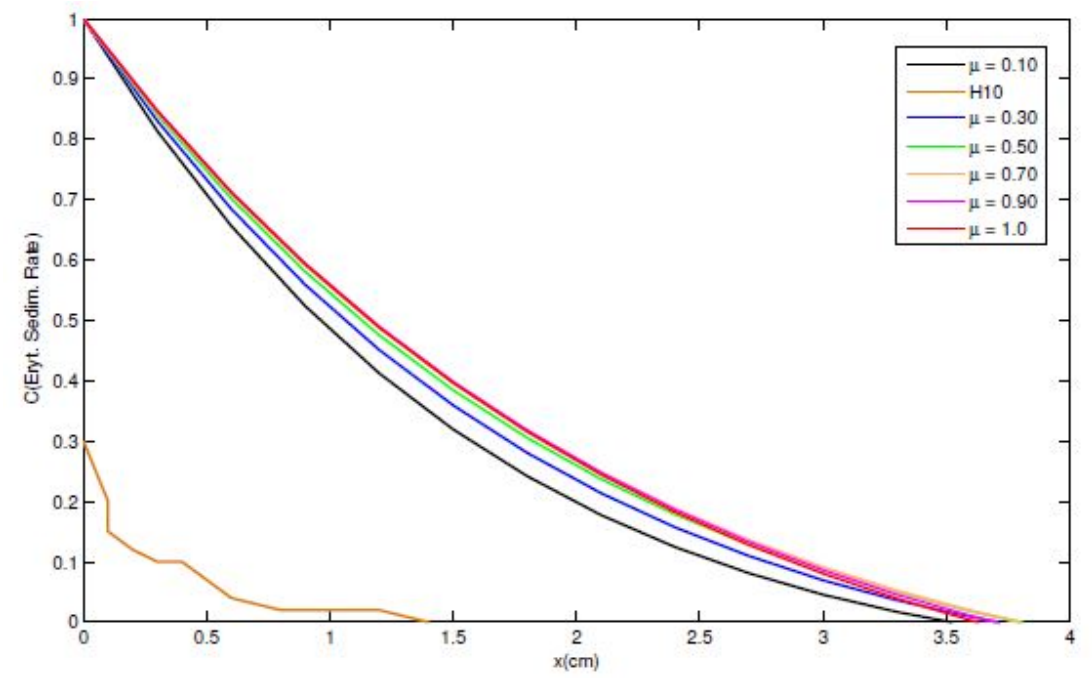


Figure 12: Graph of the data Man 12.

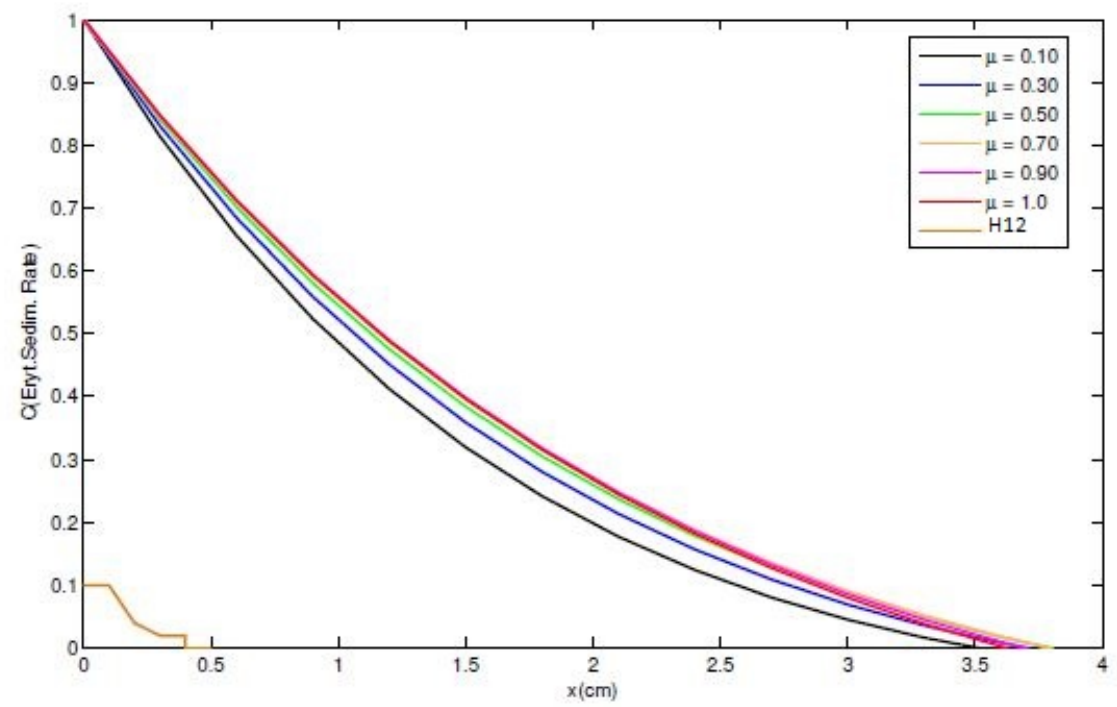

Figure 13: Graph of the data Man 14.

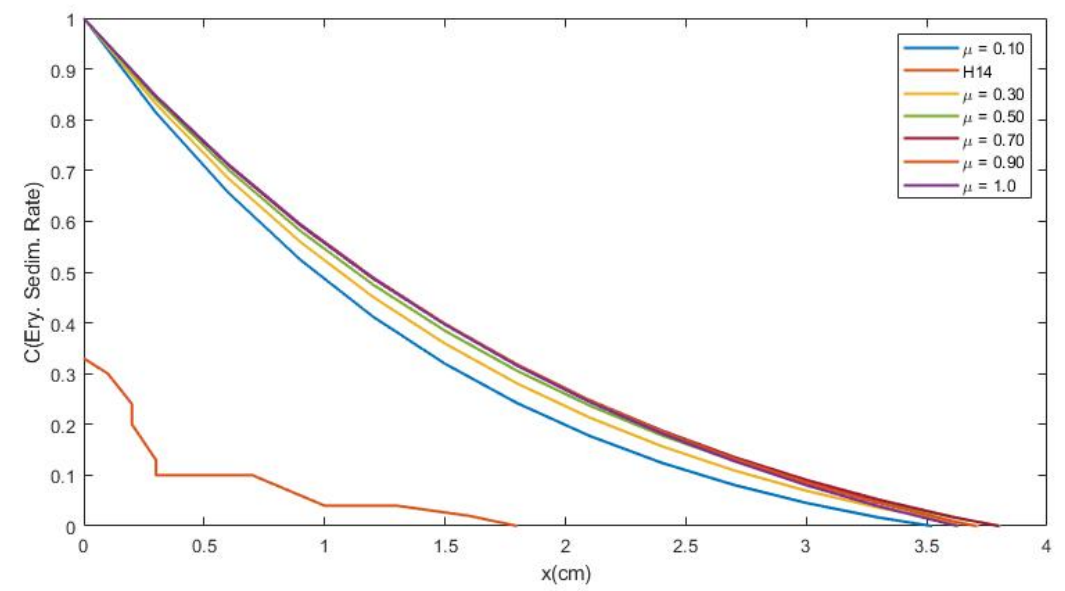


Figure 14: Graph of the data Woman 2.

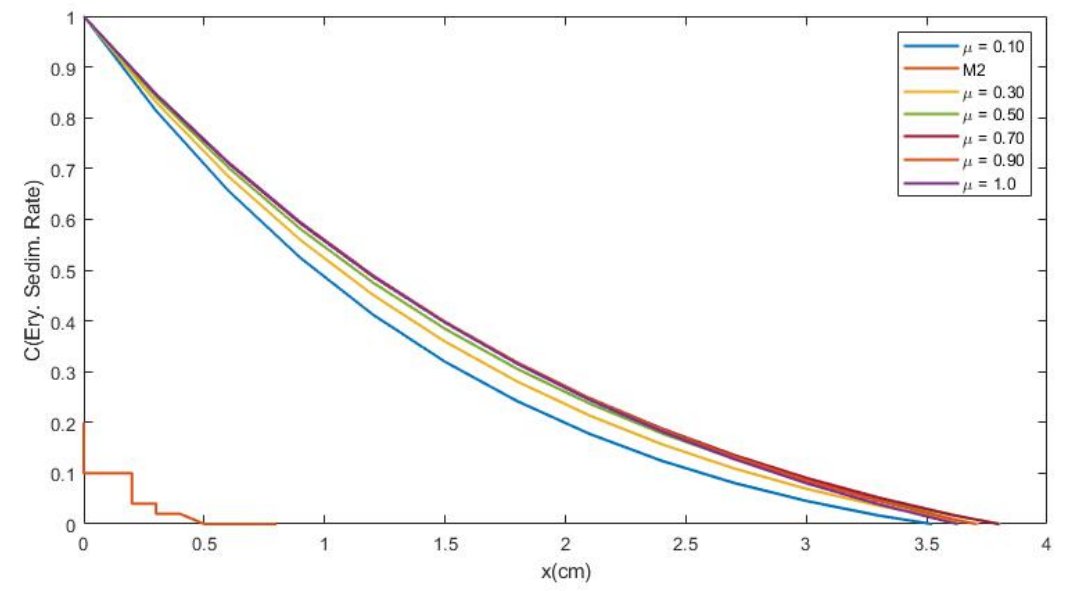

Figure 15: Graph of the data Woman 4.

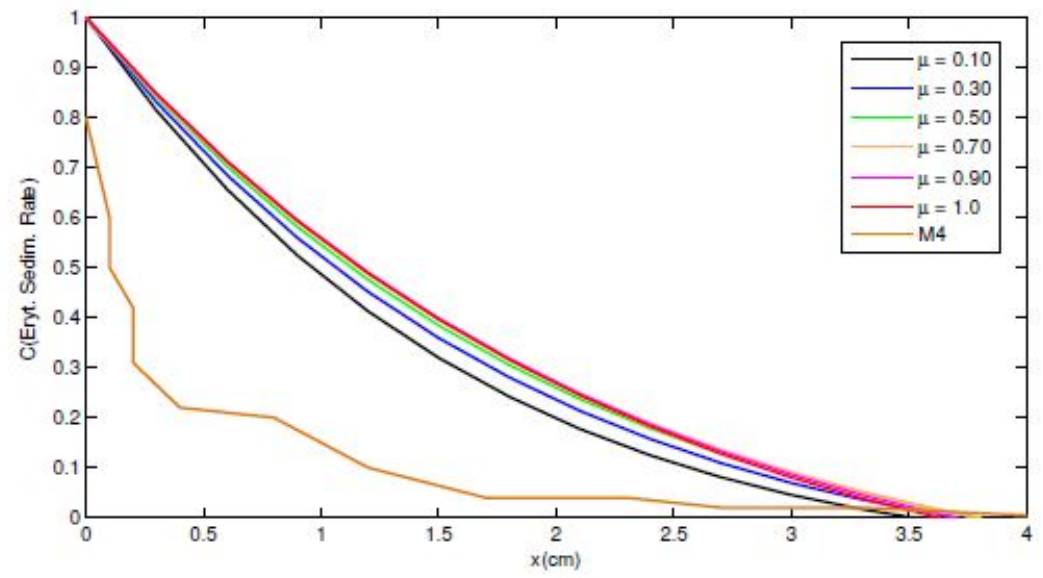


Figure 16: Graph of the data Woman 6 .

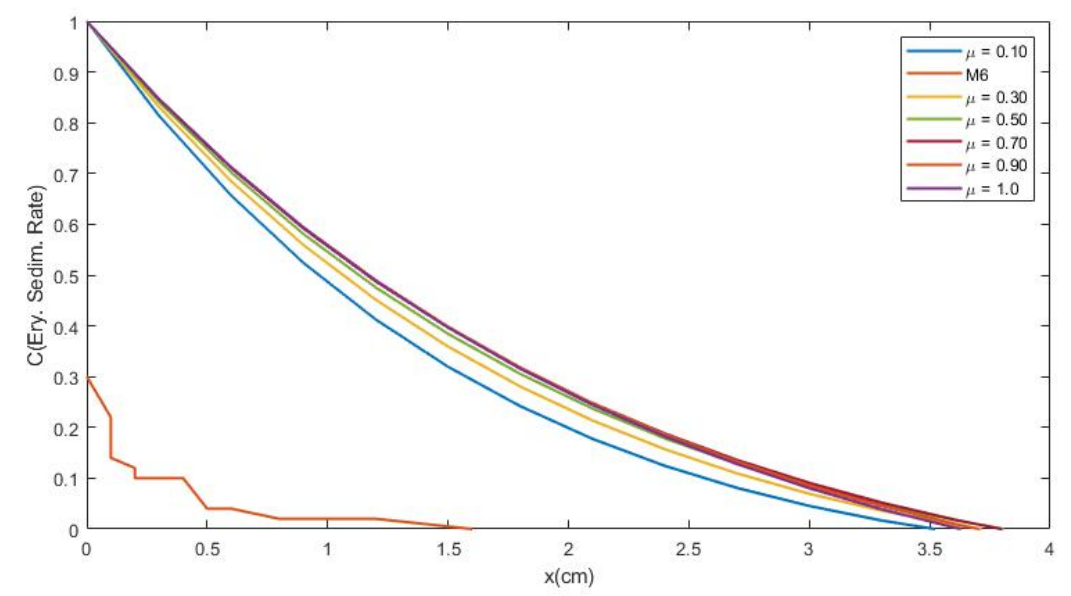

Figure 17: Graph of the data Woman 8.

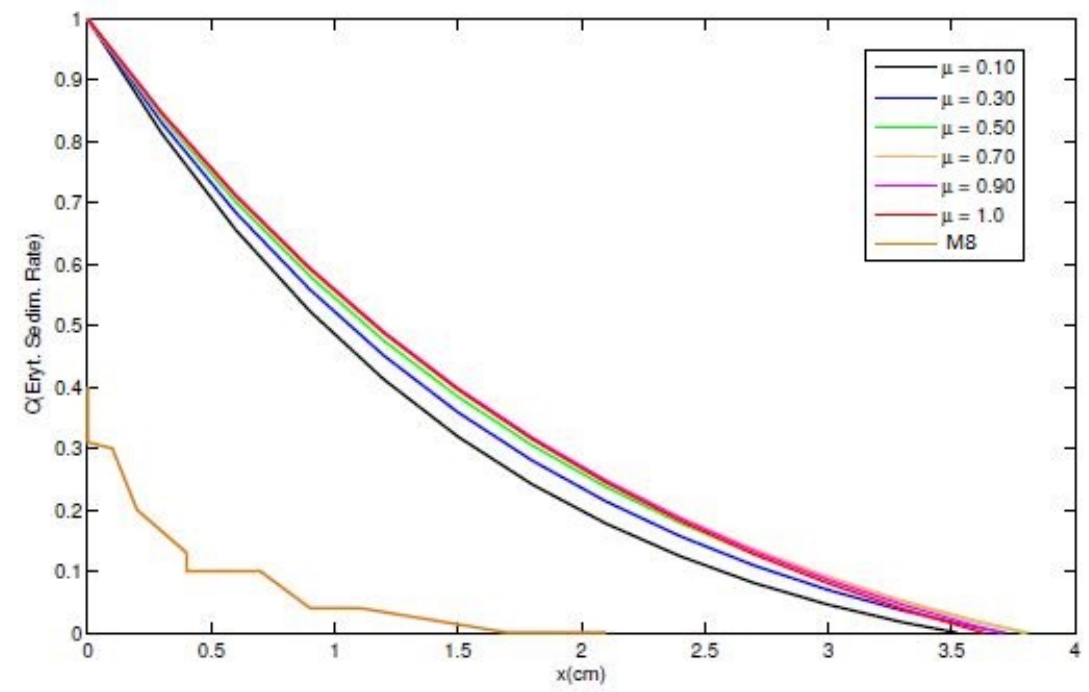


Figure 18: Graph of the data Woman 10.

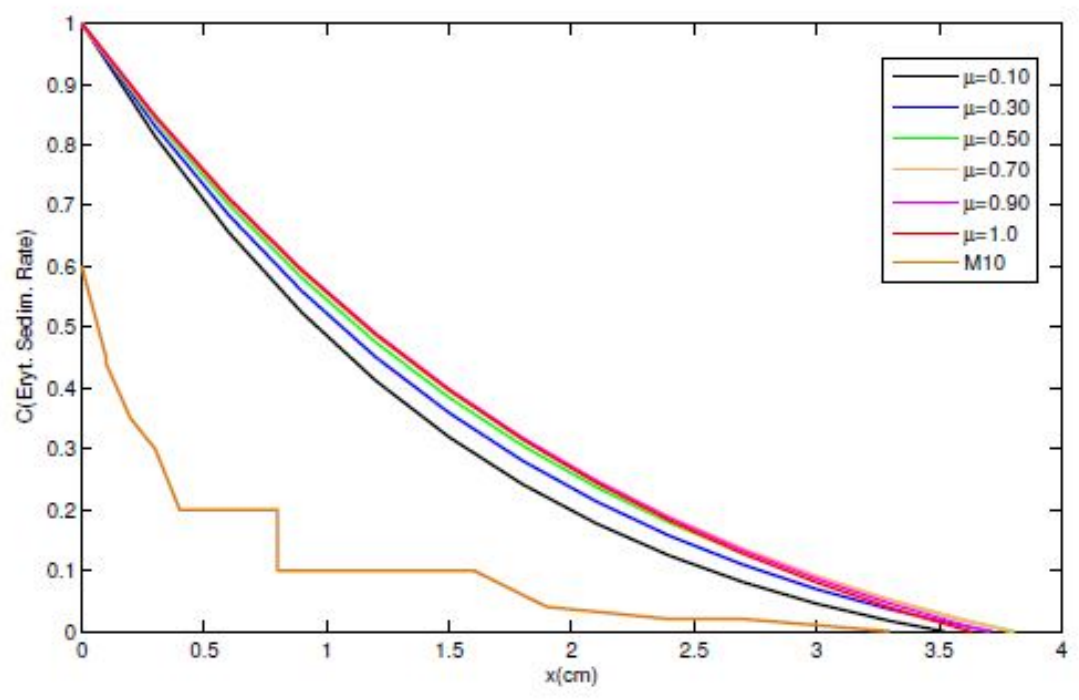

Figure 19: Graph of the data Woman 12.

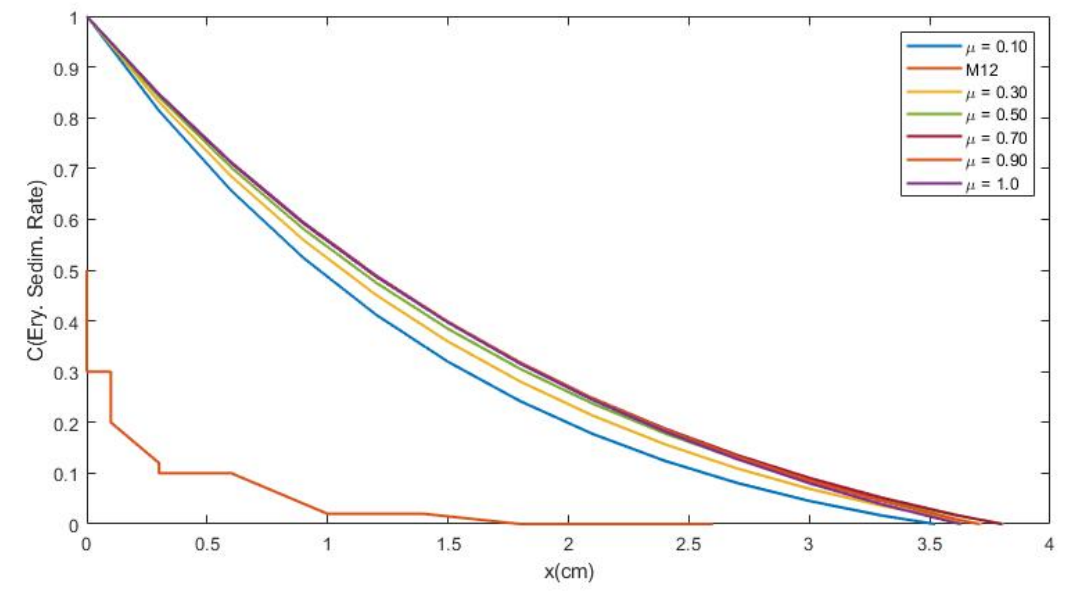


Figure 20: Graph of the data Woman 7.

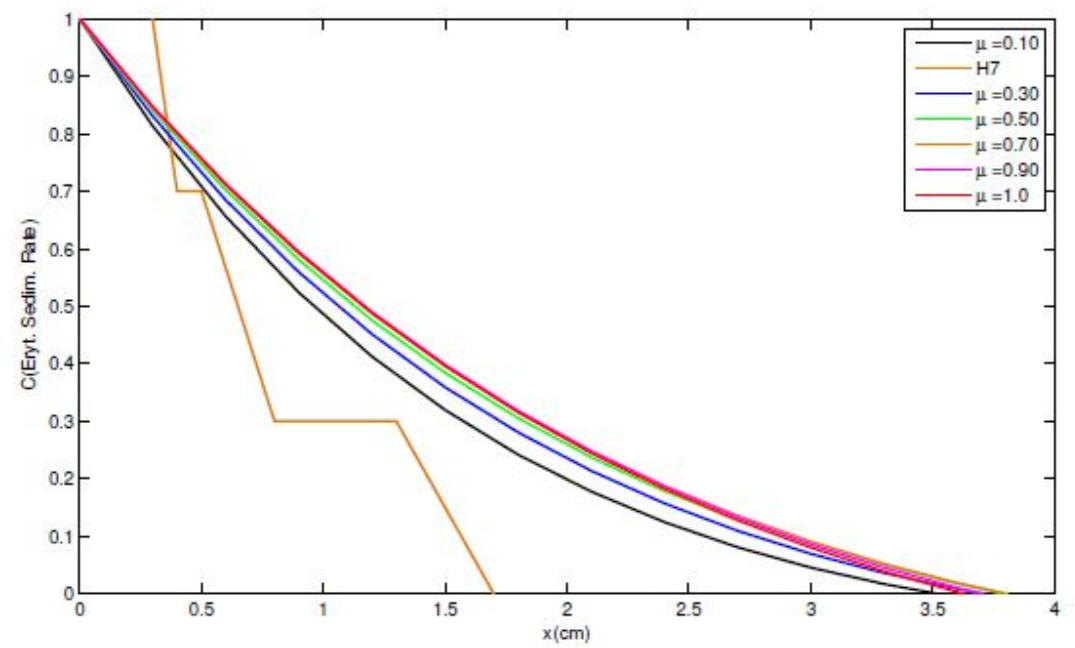

Figure 21: Graph of the data Woman 9.

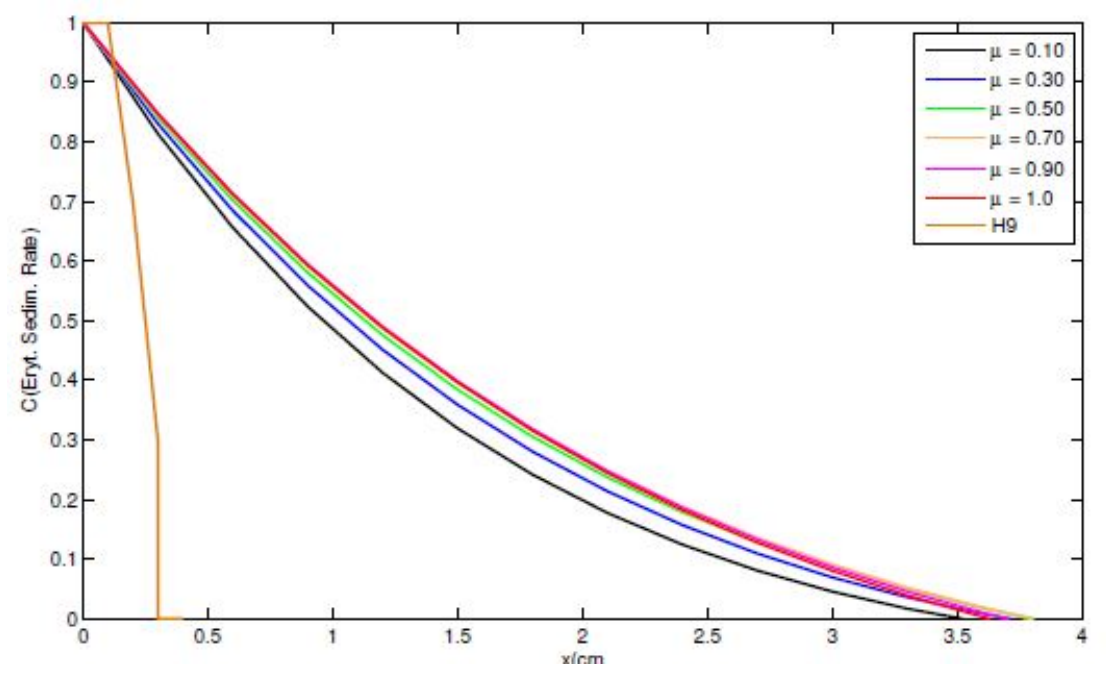


Figure 22: Graph of the data Man 11.

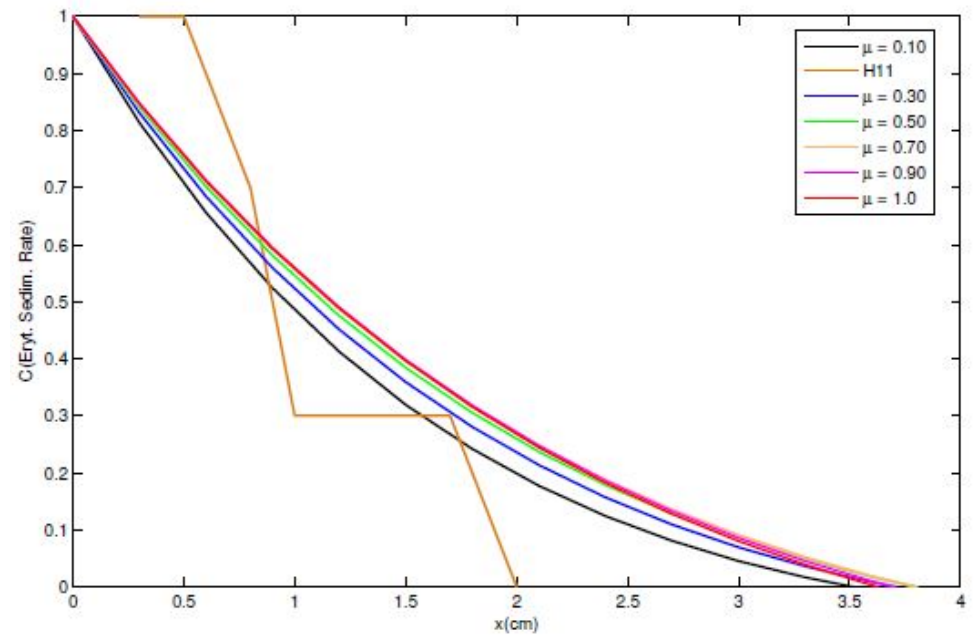

Figure 23: Graph of the data Man 13.

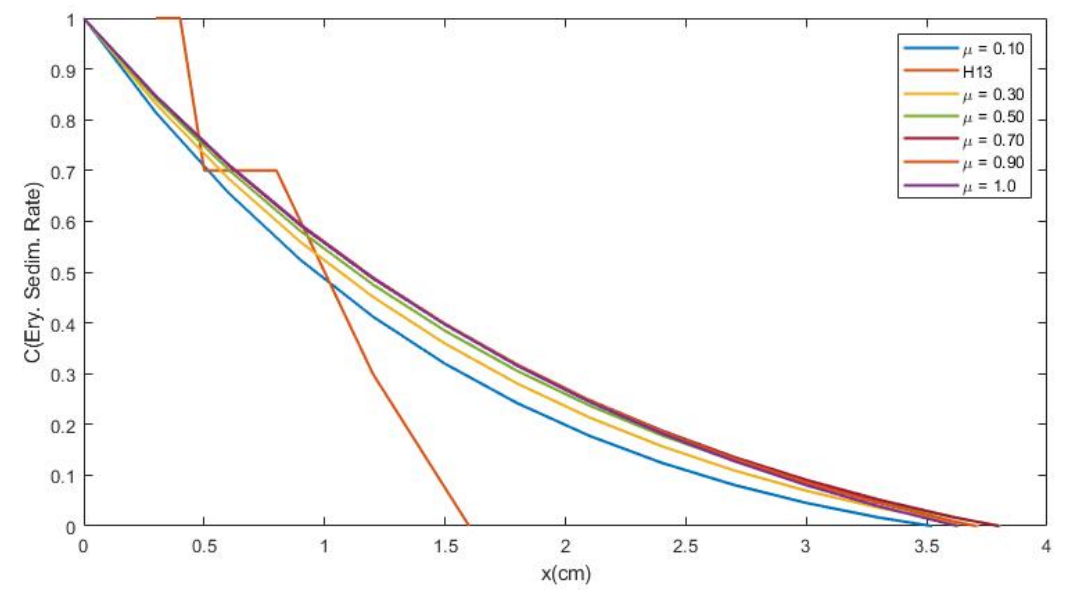


Figure 24: Graph of the data Woman 1.

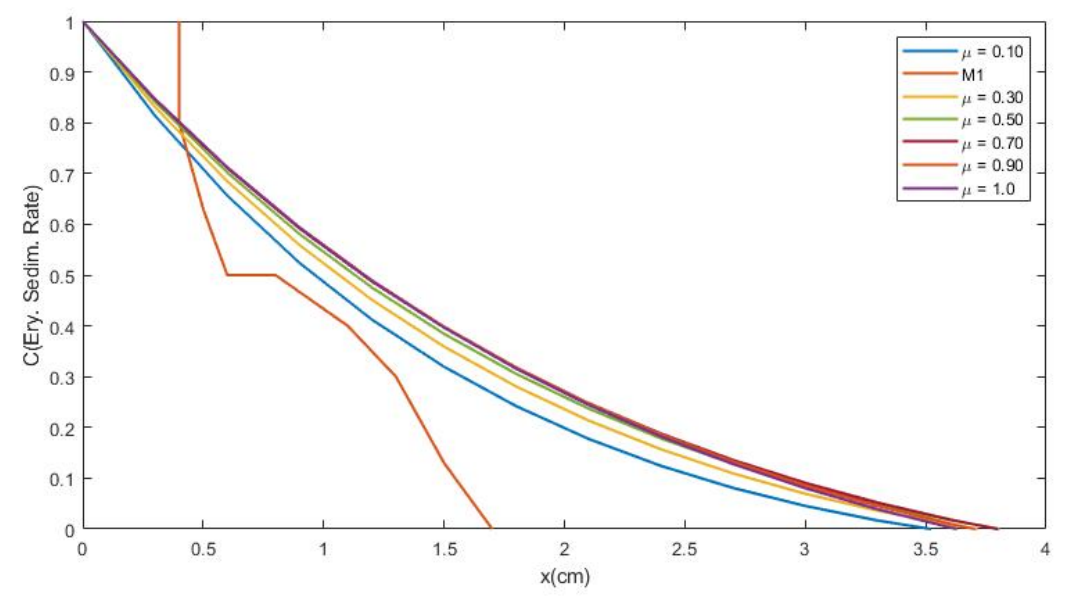

Figure 25: Graph of the data Woman 3.

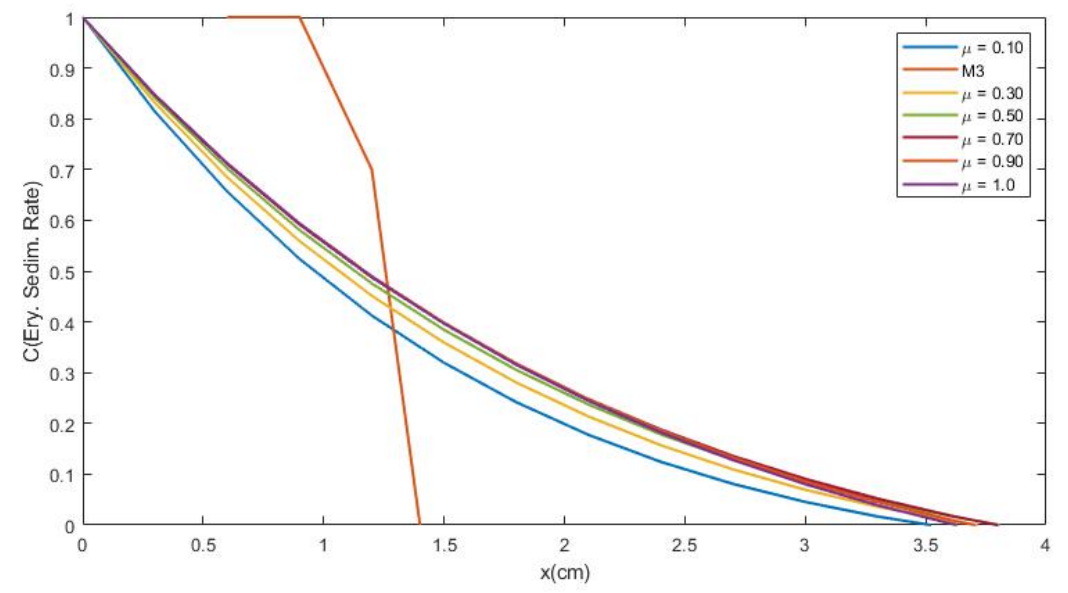


Figure 26: Graph of the data Woman 5.

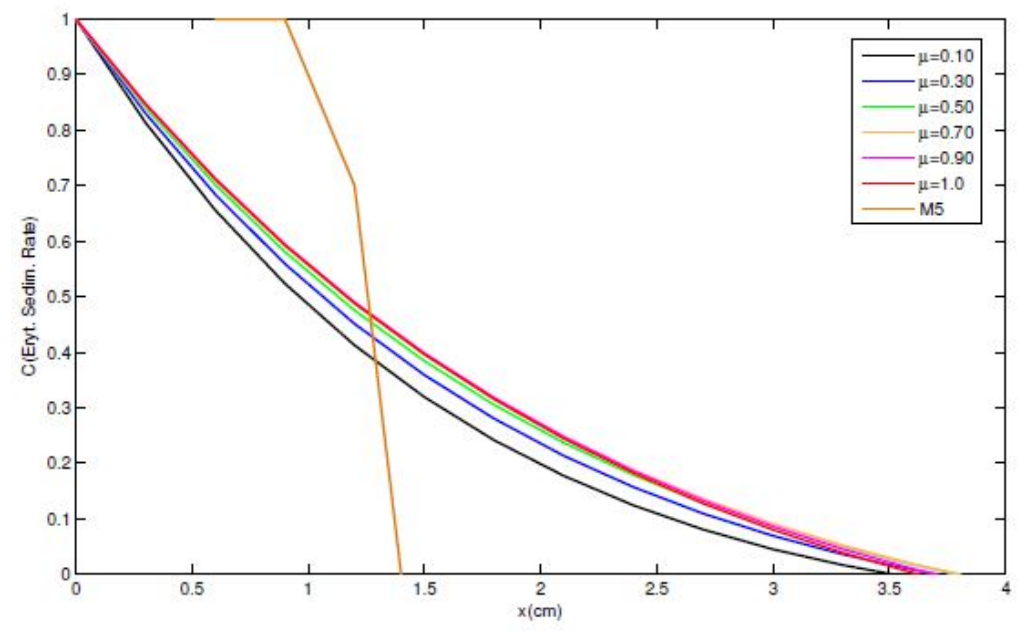

Figure 27: Graph of the data Woman 7.

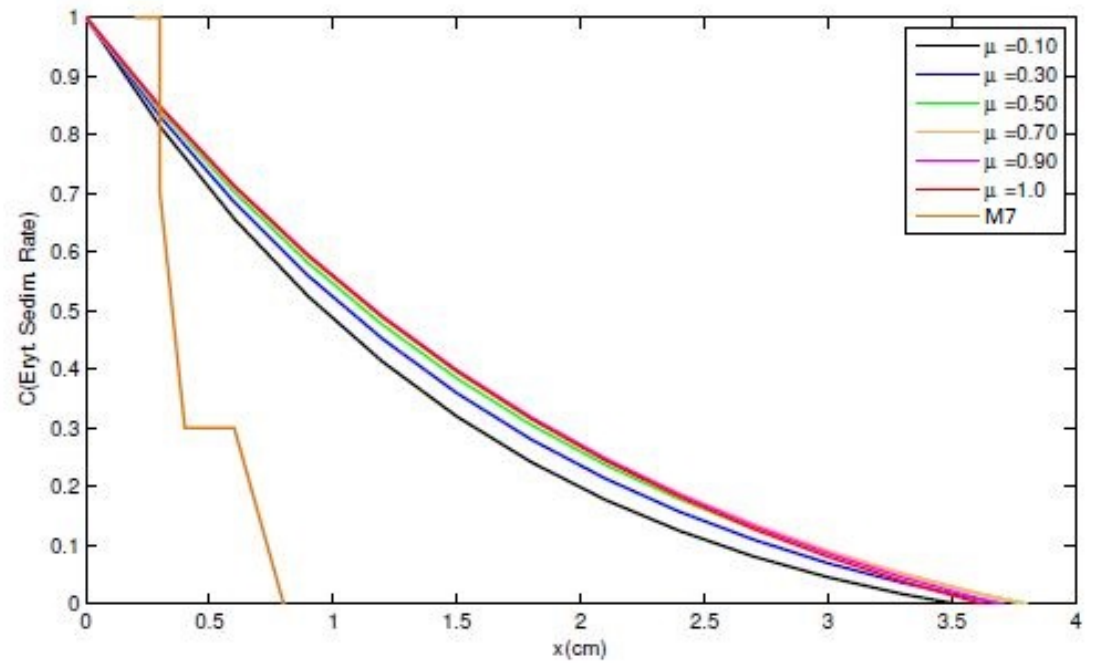


Figure 28: Graph of the data Woman 9.

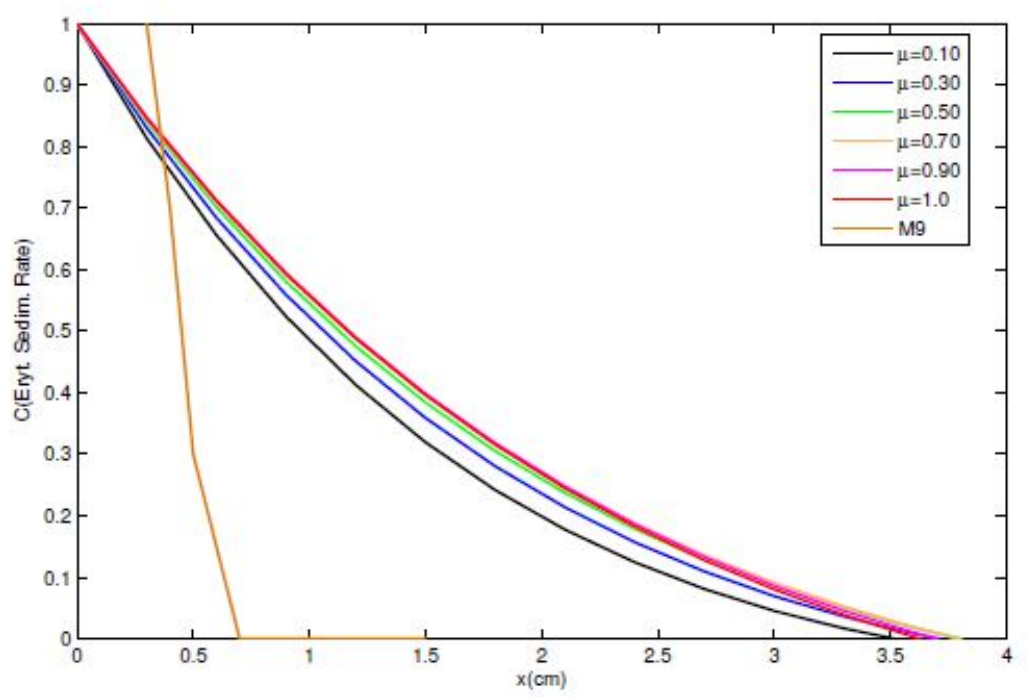

Figure 29: Graph of the data Woman 11.

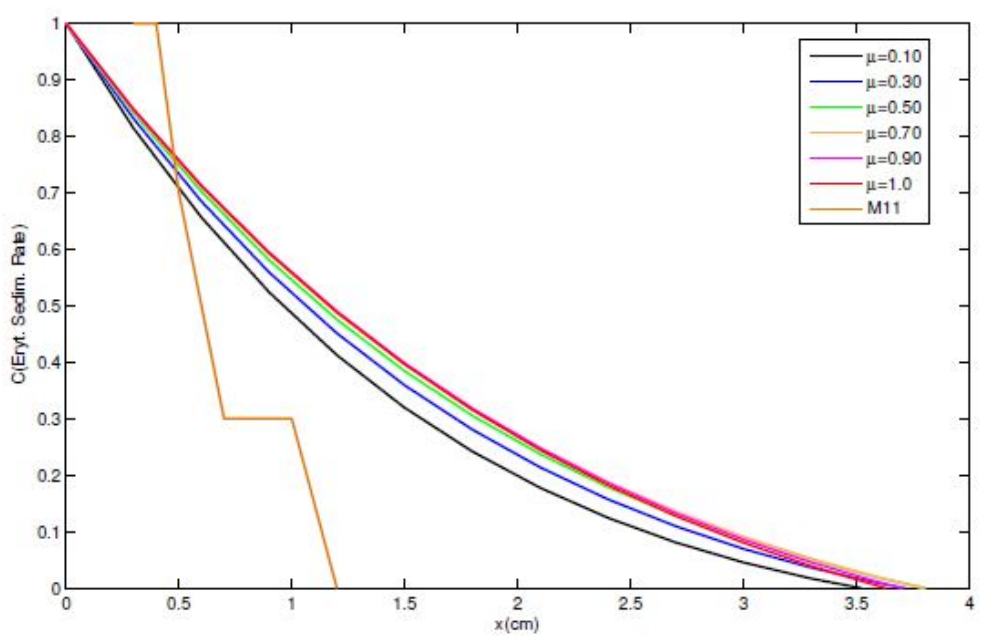


Figure 30: Graph of the data Woman 13.

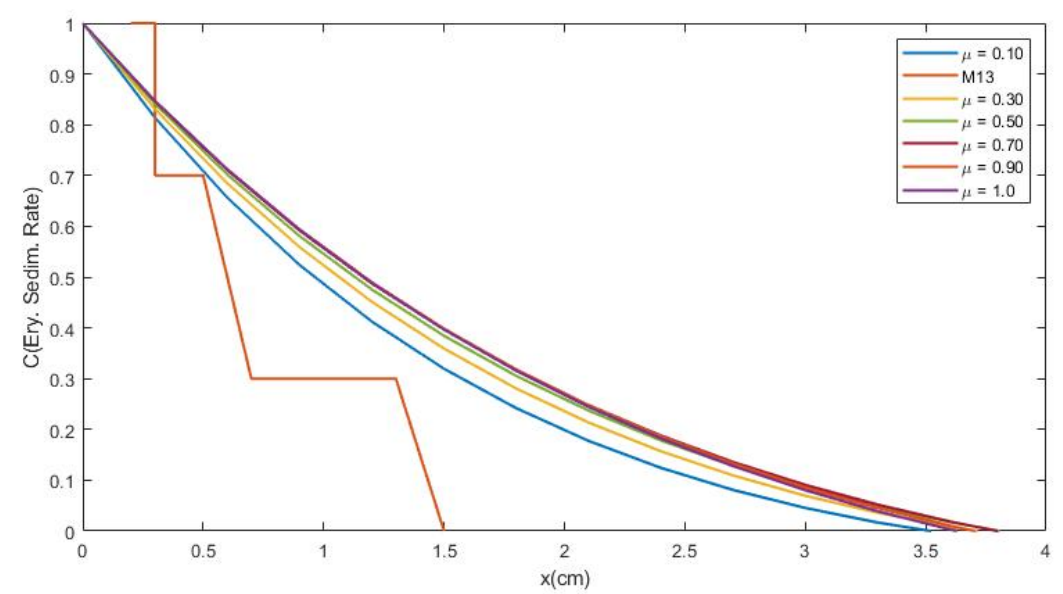

Figure 31: Graph of the data Woman 14.

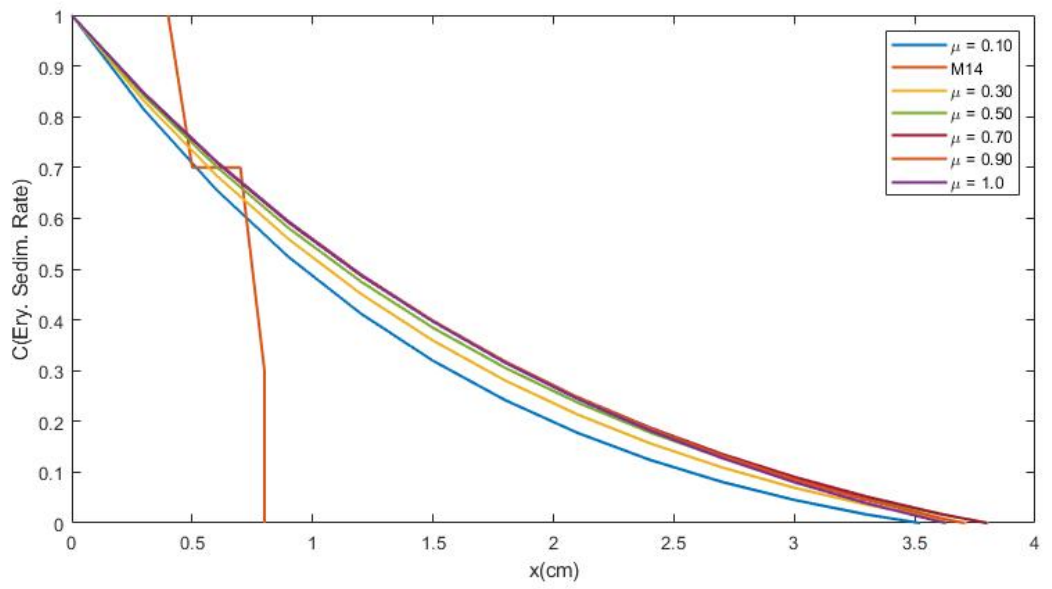

